\title{
PRODUCTION AND CHARACTERIZATION OF AL6061-GLASS PARTICULATE STIR CAST COMPOSITE
}

\author{
Madhukumar Y C $\mathbf{C}^{1}$, Umashankar ${ }^{2}$ \\ ${ }^{1}$ Research Scholar, Department of Mechanical Engineering, Siddaganga Institute of Technology, Tumkur-572103, \\ Karnataka. \\ ${ }^{2}$ Department of Mechanical Engineering, Siddaganga Institute of Technology, Tumkur-572103, Karnataka. \\ *Tel:8970906721;*E-mail: madhuyc3@gmail.com
}

\begin{abstract}
In the present investigation Al6061-Glass particulate metal matrix composite with different weight percentage of reinforcements (3\%, 6\%, 9\%, and 12\%) was prepared using melt stirring technique. The prepared composites specimens undergo tests to evaluate the wear and mechanical properties like hardness and tensile strength. The homogeneous distribution of reinforced particles in the Al6061 matrix was examined using optical microscopy and XRD analysis. by increasing the weight percentage of reinforcement particle in the matrix alloy increases the hardness and tensile strength of composites up to 9 wt\% and sudden decreases in the hardness and tensile strength for $12 \mathrm{wt} \%$ because of agglomeration of the reinforcement particles in the matrix alloy. The wear rate of the composites increases significantly by increasing the wt\% of reinforcement particles.
\end{abstract}

Keywords: Al6061, Glass Particulate, Stir Casting, XRD, Tensile Strength, Hardness, Wear

\section{INTRODUCTION}

Aluminium and its alloys are being light in weight and are the most promising matrix material for the development of aluminium metal matrix composites (AMMCs). Metal matrix composites (MMCs) posses significantly improve the mechanical properties like hardness, young's modulus, yield strength and ultimate tensile strength. By incorporating the hard ceramic particulates like boron carbide, silicon carbide, aluminium oxide, garnet, titanium dioxide, aluminium nitride into the aluminium matrix increases the wear and mechanical properties of aluminium alloys [K.K.Alaneme et al. (2012) and Bharath V et al. (2014)].

Aluminium matrix can be strengthened by reinforcing hard ceramic particulates like $\mathrm{SiC}, \mathrm{Al}_{2} \mathrm{O}_{3}, \mathrm{TiB} 2, \mathrm{~B}_{4} \mathrm{C}$ etc.

Several fabrication methods have been used for the production of metal matrix composites such as solid state methods, liquid state methods and in situ process. However, among that liquid metallurgy method is most widely used and preferred method to give uniform distribution of reinforcement particle in the matrix [William et al. (1998) and Kalaiselvan et al. (2011)]. Stir casting is the most economical method for the production of composites and gives better bonding between matrix and reinforcement [Shorowordi et al. (2003) and Hashim et al. (1999)].

Many research works have been done using $\mathrm{SiC}, \mathrm{Al}_{2} \mathrm{O}_{3}$, $\mathrm{TiB} 2$, and $\mathrm{B} 4 \mathrm{C}$ a reinforcement material and very limited research work have done using glass particulate as reinforcement in the $\mathrm{Al}$ matrix. Glass particulate is having good hardness, wear resistance and less dense $(2.53 \mathrm{~g} / \mathrm{cc})$. In the present research work using a glass particulate as a reinforcement of size 75 microns with 3 wt $\%$ to $12 \mathrm{wt} \%$ weight percentages added into the aluminium matrix at a temperature of $750^{\circ} \mathrm{c}$ by melt stirring. Further, the prepared composites were undergoing the evaluation of mechanical and wear properties.

\section{MATERIALS AND METHODS}

\subsection{Materials}

In this research work Al6061 has been used as matrix material. The elemental composition of matrix material is as shown in table1.It was obtained in the form of billets. To fabricate composite Glass particulate was used as a reinforcing material. The percentage of glass particulate was taken as 3,6,9,12 wt \% particulate with a size of 75 microns.

Table 1: Elemental composition of the Aluminium 6061

\begin{tabular}{ccccccccc}
\multicolumn{10}{c}{ alloy } \\
\hline Elements & $\mathrm{Cu}$ & $\mathrm{Mg}$ & $\mathrm{Si}$ & $\mathrm{Fe}$ & $\mathrm{Mn}$ & $\mathrm{Cr}$ & $\mathrm{Zn}$ & $\mathrm{Al}$ \\
\hline $\mathrm{Wt} \%$ & 0.4 & 1.2 & 0.8 & 0.7 & 0.15 & 0.45 & 0.25 & $\mathrm{Bal}$ \\
\hline
\end{tabular}

\subsection{Fabrication of Composites}

The Composite was prepared by using melt stirring method. Initially, Al6061 alloy billets were taken into graphite crucible and melted to a temperature of $750^{\circ} \mathrm{c}$ using resistance furnace. In order to remove the absorbed gases from the glass particulate. The glass particulates are preheated to a temperature of $250^{\circ} \mathrm{c}$ in an oven. After degassing and slag removal the melt was stirred continuously with help of stirrer to get a fine vortex. The preheated glass particulates were added into the vortex of the molten alloy and continuously stirring the slurry for 10 minutes at 250rpm to get the homogenous distribution of the 
reinforcement in the molten Al6061 alloy [K.V Sreenivas Rao et al. (2016) and V.Auradi et al. (2014)]. The pouring was done at a temperature of $775^{\circ} \mathrm{c}$ into a preheated permanent mould after holding the melt for an interval of 1 2 minutes.

\subsection{Microstructural Examination}

From castings, the samples were cut and polished as per metallographic procedure for Microstructural examination using optical microscopy as shown in Figure 1 (Olympus Microscope). In this study, a Keller's etchant was used to reveal the microstructure. XRD analysis was conducted to identify the presence of glass particulate in Al 6061 matrix.

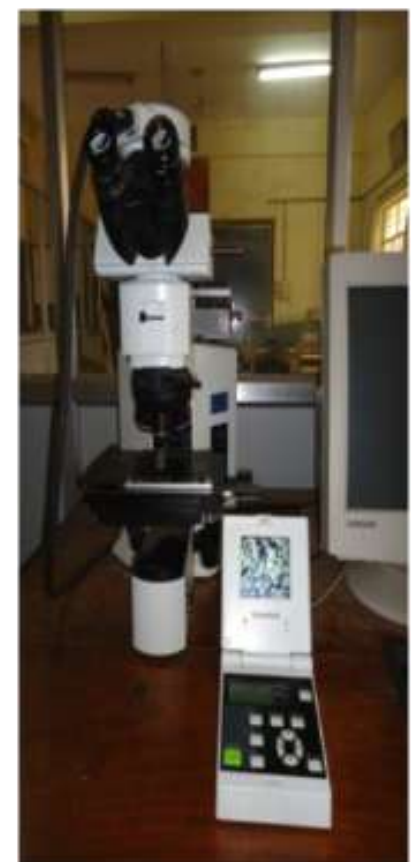

Figure 1: Optical microscopy

\subsection{Tensile Strength Testing}

From the composites, the tensile specimens are machined as per ASTM E08M dimensions as shown in Figure 2. The tension tests were conducted using a servo-hydraulic uniaxial testing machine.

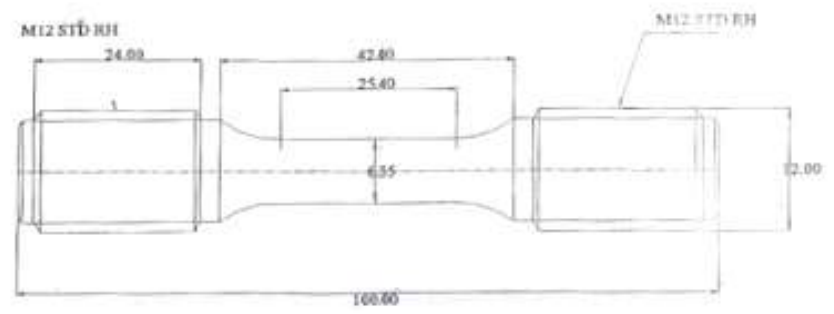

Figure 2: ASTM dimension for tensile specimen

\subsection{Hardness Test}

The micro hardness test was conducted on polished specimens using Zwick micro Vicker-hardness tester as shown in Figure 3 under a load of 50 grams for 10 seconds at 15 different locations and taking the average value of micro hardness.

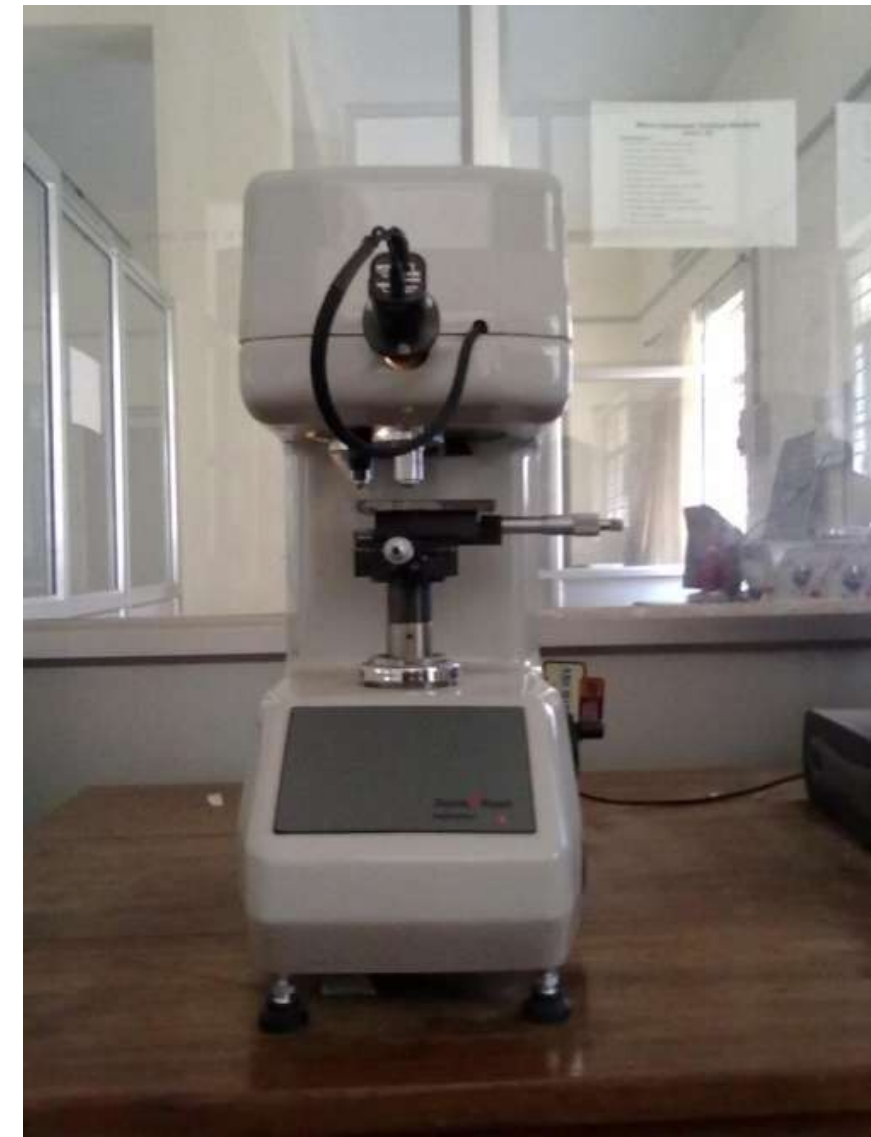

Figure 3: Zwick Micro Vicker's hardness testing machine

\subsection{Wear Testing}

The wear test specimens are machined as per ASTM G99 dimension $(30 \mathrm{~mm} \times 8 \mathrm{~mm})$ test were conducted using pin-ondisc wear testing apparatus. The wear test specimen was ground using a different abrasive grade paper and it is cleaned with acetone to remove any wear waste.

\section{RESULTS AND DISCUSSION}

\subsection{Microstructure}

It is cleared from the Figure 4 that glass particulate is homogeneously distributed in the Al 6061 matrix generally because of good stirring of slurry and density difference between matrix and reinforcement. Preheating of the reinforcement gives rise to better bonding between matrix and reinforcement. Homogeneous distribution of reinforcement in the matrix increases the mechanical properties of the matrix.

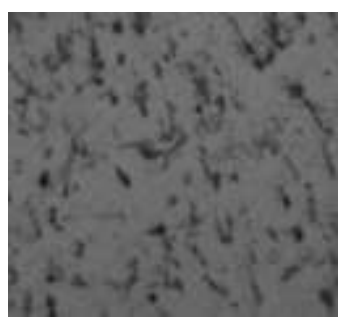

(a)

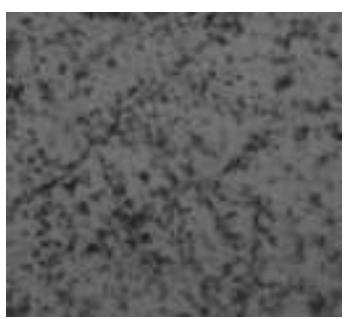

(b) 


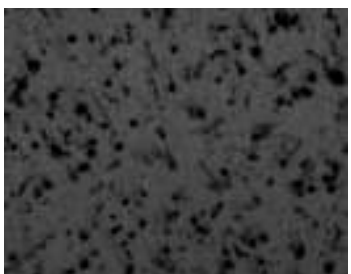

(c)

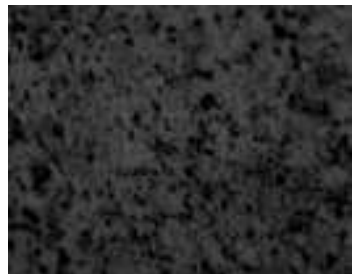

(d)
Figure 4: Distribution of Glass particulate in (a) 3\%, (b) $6 \%$, (c) $9 \%$, and (d) $12 \%$ composites

\subsection{Mechanical Properties}

It is clear from Figure 5 that the microhardness of composites increases by increasing the weight percentage of glass particulates up to $9 \mathrm{wt} \%$. Basically, $\mathrm{Al} 6061$ matrix is a soft alloy for which if add the hard ceramic particles like glass particulate in which hard ceramic particles having their existing property of hardness transfers to soft matrix effectively act a barrier for the movement of dislocation which increases the hardness. The homogeneous distribution particles in composites up to $9 \mathrm{wt} \%$ because of that the microhardness value increased and there is sudden the decrease in micro hardness value for $12 \mathrm{wt} \%$ because of agglomeration and porosity in the composites.

It is clear from Figure 6 that the tensile strength of composites increases by increasing the weight percentage of glass particulates up to $9 \mathrm{wt} \%$. It can be observed that glass particulates are very effectively improved the tensile strength of composites from 119Mpa to 141Mpa. The incorporating of glass particulate into the matrix which gives rises to more strength a matrix. composites strength were increased for the two reasons of difference in a thermal mismatch between the matrix and the reinforcement and dislocation pile-up increases the strength up to $9 \mathrm{wt} \%$ because the particle distribution is homogeneous. Sudden decreases in strength for $12 \mathrm{wt} \%$ because of particle agglomeration in the composites. [K.Kalaiselvan et al. (2011) and Joel Hemanth et al. (2011)].

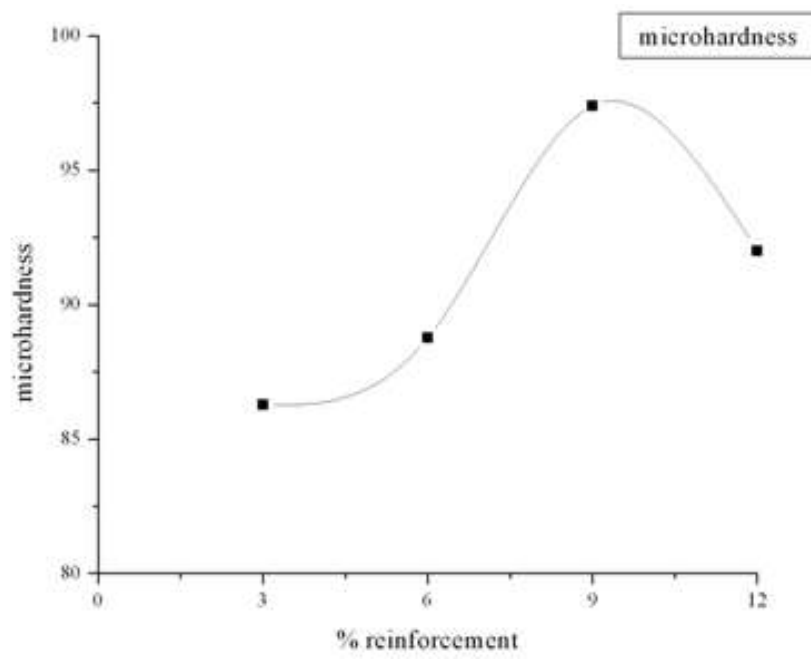

Figure 5: plot shows variation in micro Hardness of composites

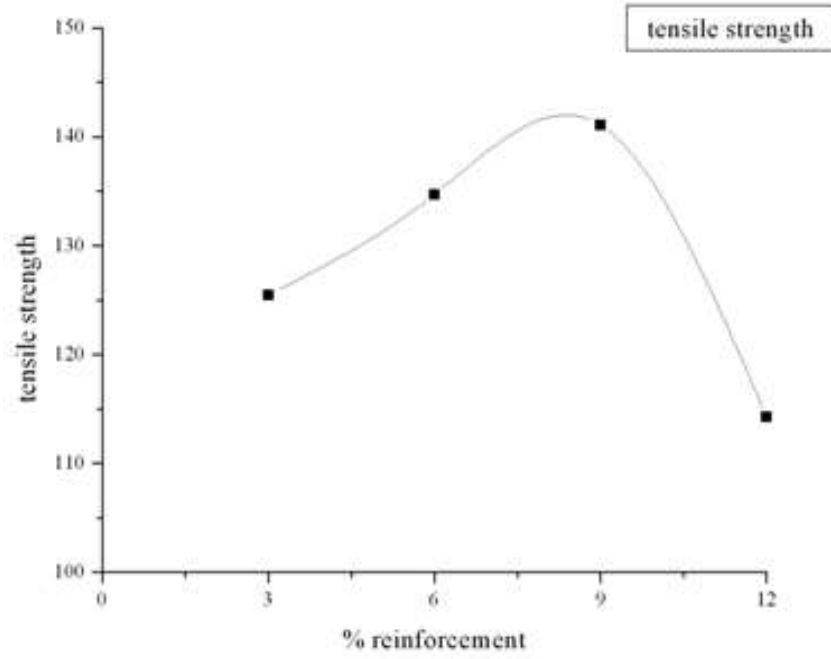

Figure 6: plot shows variation in tensile strength of composites

\subsection{Wear Behaviour}

From the graph clearly shows that wear rate of composites is increased by increasing the weight percentage of glass particulate as shown in Figure 7. [Joel Hemanth et al. (2011)]. The increased wear rate of the composite reinforced with glass particulates are caused to increase the hardness and strength.

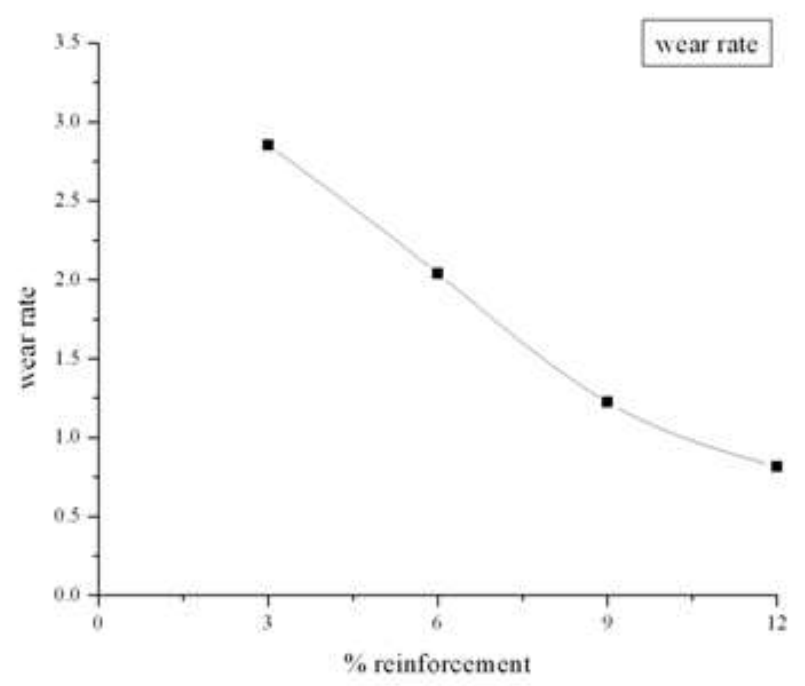

Figure 7: change in wear rate with wt $\%$ of reinforcement

\subsection{XRD Analysis}

The composites prepared by stir casting technique were analyzed by using X-ray powder diffraction technique used to identify materials. In present research work the X-ray powder diffraction was analyzed for identify glass particulates. From Figure 8 XRD analysis represents the confirmation of glass particulate in the composite. 


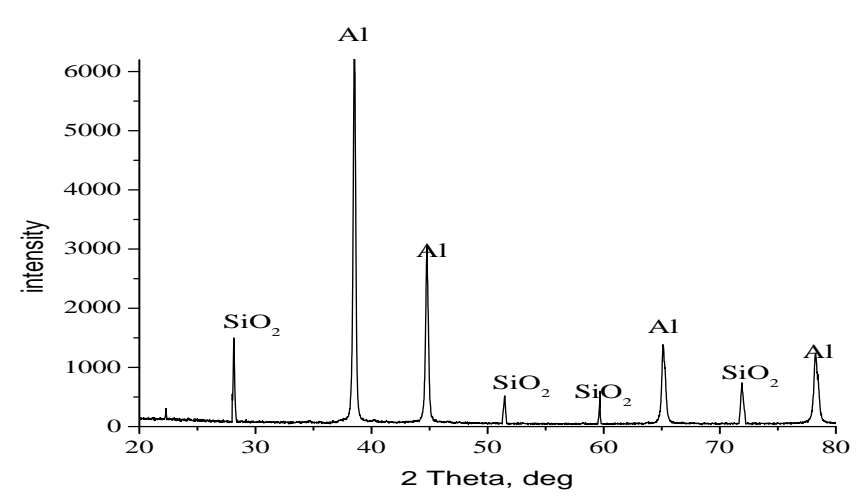

Figure 8: XRD pattern of Al6061-glass particulate composites

\section{CONCLUSIONS}

In the present investigation, the Al-glass particulates composites were synthesized by melt stirring method with weight percentage $(3 \%, 6 \%, 9 \%$ and $12 \%)$ of reinforcement. A microstructural and XRD study reveals the homogeneous distribution of glass particulates in the Al 6061 matrix. Microhardness and tensile strength of composites were increased by increasing the weight percentage of glass particulates. Wear rate of composites has increased by increasing the weight percentage of reinforcement.

\section{REFERENCES}

[1] K.K.Alaneme, A.O. Aluko (2012) Fracture toughness and tensile properties of as-cast and age-hardened aluminium 6063-silicon carbide particulate composites. Scientia iranica 19 (4): 992-996

[2] Bharath V, V. Auradi (2014) Preparation of 6061Al$\mathrm{Al}_{2} \mathrm{O}_{3}$ MMCs by stir casting and evaluation of mechanical and wear properties. Procedia Materials science (6):1658-1667

[3] K.V Sreenivas Rao, T.P Bharathesh (2016) Dry sand abrasive wear behaviour of chill cast aluminium boron carbide composites. Journal of engg and applied science. Vol1 (1) no.1

[4] Rajesh G.L, V.Auradi (2014) processing of $\mathrm{B}_{4} \mathrm{C}$ particulate reinforced 6061 aluminium matrix composites by melt stirring involving two-step addition. Procedia Materials science (6):1068-1076

[5] Joel Hemanth (2011) Abrasive and slurry wear behaviour of chilled aluminium alloy A356 reinforced with fused silica metal matrix composite. Composites part B (42):1826-1833

[6] B.vijayaramnath, S.Rajesh (2014) Evaluation of mechanical properties of aluminium alloy-aluminaboron carbide metal matrix composites. Materials and design (58):332-338

[7] K.Kalaiselvan, N.Murugan (2011) Production and characterization of AA6061- $\mathrm{B}_{4} \mathrm{C}$ stir cast composite. Materials and design (32):4004-4009

[8] J.Jebeen Moses, I.Dinaharan (2014) Characterization of silicon carbide particulate reinforced AA6061 aluminium alloy composites produced via stir casting. Procedia Materials science (5):106-112
[9] Gopalakrishnan s, Murugan N (2011) Prediction of tensile strength of friction stir welded aluminium matrix $\mathrm{TiC}_{\mathrm{p}}$ particulate reinforced composite. Materials Design (32): 462

[10] Hashim J, Looney L (1999) Metal matrix composites production by the stir casting method. J.Mater. Process. Technol (92): 931

[11] Ramesh CS, Keshavamurthy R (2009) Microstructure and mechanical properties of $\mathrm{Ni}-\mathrm{P}$ coated $\mathrm{Si}_{3} \mathrm{~N}_{4}$ reinforced Al6061 composites. Material science and engg A (A528): 8765

[12] William C, Harrigan (1998) Commercial processing of metal matrix composites. Material science and engg A (244): 75

[13] Shorowordi KM, Laoui T, Haseeb ASMA (2003) Microstructure and interface characteristics of $\mathrm{B}_{4} \mathrm{C}, \mathrm{SiC}$ and $\mathrm{Al}_{2} \mathrm{O}_{3}$ reinforced $\mathrm{Al}$ matrix composites a comparative study. J Mater Process Technol (142): 738 